\title{
The radiolytic behavior and mechanism of calixarene crown ether under $\gamma$-irradiation
}

\author{
AO YinYong ${ }^{1}$, PENG Jing ${ }^{1}$, ZHANG YouWei ${ }^{1}$, YUAN LiYong ${ }^{2}$, YU ChuHong ${ }^{1}$, \\ LI JiuQiang $^{1} \&$ ZHAI MaoLin ${ }^{1 *}$ \\ ${ }^{1}$ Beijing National Laboratory for Molecular Sciences (BNLMS), Department of Applied Chemistry, College of Chemistry and Molecular \\ Engineering, Peking University, Beijing 100871, China; \\ ${ }^{2}$ Institute of High Energy Physics, Chinese Academy of Sciences, Beijing 100049, China
}

Received September 3, 2012; accepted October 25, 2012; published online February 26, 2013

\begin{abstract}
Bis(2-propyloxy)calix[4]crown-6 (BPC6) is an effective separation agent for cesium removing from spent nuclear fuel. The study on radiolytic behavior of BPC6 itself under $\gamma$-irradiation was required for evaluating its feasibility of practical application. It was found that BPC6 exhibited excellent radiation stability at dose less than $100 \mathrm{kGy}$. However, the isopropyl groups in BPC6 underwent oxidation and dealkylation to form carbonyl groups and phenolic hydroxyl groups at dose above $300 \mathrm{kGy}$, respectively. When the dose was more than $1000 \mathrm{kGy}$, the ring opening of crown ether structure of BPC6 resulted in the formation of phenolic hydroxyl groups as well. The formation of radiolytic products containing phenolic hydroxyl groups during the irradiation of BPC was confirmed by using $\mathrm{FeCl}_{3}$ as a probe. Combining with the radiolytic behavior of two model chemicals (1-isopropoxybenzene and benzo-18-crown- 6 ether), the radiolytic behavior and mechanism of BPC6 under $\gamma$-irradiation was testified further.
\end{abstract}

calixarene crown ether, $\gamma$-irradiation, radiation stability, phenolic hydroxyl groups

Citation: $\quad$ Ao Y Y, Peng J, Zhang Y W, et al. The radiolytic behavior and mechanism of calixarene crown ether under $\gamma$-irradiation. Chin Sci Bull, 2013, 58: 1663-1669, doi: 10.1007/s11434-013-5667-8

${ }^{137} \mathrm{Cs}$ is a major radioactive fission product and one of the most dangerous isotopes during the reprocessing of spent nuclear fuel (SNF). Moreover, it contributes a large part of heat load and radiation in high level liquid waste with a long half-life $(30.1 \mathrm{y})$. The removal of $\mathrm{Cs}^{+}$ions from the nitric acid slurries prior to further waste disposal can thus not only greatly simplify the subsequent waste handling and storage, but also protect the human health and environment. Calixarene crown ethers (CCEs), as macrocyclic receptors, with high efficiency and selectivity in metal ion binding have been utilized to extract isotopes from SNF [1-7]. Among the CCEs, bis(2-propyloxy)calix[4]crown-6 (BPC6) receives increasing attentions as a novel extractant for selective removal of $\mathrm{Cs}^{+}$from SNF [8,9], even in the presence of large amounts of alkali ions including $\mathrm{Na}^{+}, \mathrm{K}^{+}$and so on

*Corresponding author (email: mlzhai@pku.edu.cn)
[10-16].

The extracting agent will be exposed to ionizing radiation generated by radionuclides during the treatment of high level nuclear wastes. Therefore, the radiation stability of BPC6 is thus of great importance for the assessing application feasibility in nuclear fuel recycle [17-19]. Jankowski and co-workers [20-23] investigated the radiolytic behavior of BPC6 based extraction system under $\gamma$-irradiation by ESI-MS and HPLC. Their results suggested that about $40 \%$ of neat BPC6 remained unchanged up to $3000 \mathrm{kGy}$, whereas the radiolytic mechanism of BPC6 have not been clarified because of this system including various components. And there is an urgent need to investigate the radiolytic behavior of BPC6 itself.

Since the structure of BPC6 mainly contains three parts: crown ether, isopropyl and calixarene, the radiation stability of 1-isopropoxybenzene (IB) and benzo-18-crown-6 ether 
(BC) was also assessed as model chemicals under the same conditions for comparison (Figure 1). The radiolysis of BPC6 was studied with various spectroscopic methods. Based on the analysis of the radiolytic products of BPC6, combined with the investigation about radiolytic behavior of IB and $\mathrm{BC}$, the radiation effect on the chemical structure of BPC6 was discussed.

\section{Experimental}

\subsection{Materials}

The BPC6 solid (with a purity $>96 \%$ ) was obtained from Institute of Nuclear and New Energy Technology, Tsinghua University, and the synthesis and purification of BPC6 have been reported previously $[24,25]$. The impurity in the BPC6 (less than 4\%) was analyzed by ESI-MS spectrometry, and the results indicated that the chemical structure of impurity was similar with that of BPC6 (Figure S1). It is very difficult to purify BPC6. Therefore, all the experiments were carried out based on the assumption that the radiolytic behavior of the impurity is similar with that of BPC6. IB was purchased from FluoroChem Ltd (Hadfield, UK). BC was supplied by Tokyo Chemical Industry Co., Ltd (Tokyo, Japan). These compounds were used as received prior to irradiation. $\mathrm{FeCl}_{3}$ was procured from Sinopharm Chemical Reagent Corporation (Shanghai, China). All other solvents were analytical-grade reagent and used without further purification.

\subsection{Irradiation of BPC6}

The irradiation of samples was carried out at room temperature under air using ${ }^{60} \mathrm{Co}$ source (Department of Applied Chemistry of Peking University, China) in the dose range from 0 to $2200 \mathrm{kGy}$. The absorbed dose was determined by Fricke dosimeter.

\subsection{Characterization}

The Ultraviolet visible (UV-vis) spectroscopies of the samples dissolved in acetonitrile were measured by a Hitachi 3010 UV-vis spectrophotometer. Micro Fourier transform infrared spectroscopies (Micro-FTIR) of the samples under different doses were recorded on a Thermo Scientific Micro Fourier transform infrared spectrometry. The ${ }^{1} \mathrm{H}$ NMR and ${ }^{13} \mathrm{C}$ NMR spectra were recorded on Bruker AV-400 MHz nuclear magnetic resonance spectrometer apparatuses-with trichloromethane- $d\left(\mathrm{CDCl}_{3}\right)$ or dimethyl sulfoxide- $d_{6}(\mathrm{DMSO})$ as solvent.

\section{$1.4 \mathrm{FeCl}_{3}$ probe analysis}

$\mathrm{FeCl}_{3}$ ethanol solution was employed as a probe for detecting the phenolic hydroxyl groups in radiolytic products. The concentration of BPC6 is $1.8 \times 10^{-3} \mathrm{~mol} \mathrm{~L}^{-1}$ for all the samples and the concentration of $\mathrm{FeCl}_{3}$ solution is $1.0 \times 10^{-3} \mathrm{~mol} \mathrm{~L}^{-1}$.

\section{Results and discussion}

\subsection{The radiolytic behavior of BPC6 under $\gamma$-irradiation}

The $\gamma$-radiation effect on the chemical structure of BPC6 was firstly assessed by UV-vis analysis (Figure 2). Compared with that of unirradiated BPC6, the absorbance of irradiated BPC6 is strengthen in the whole ultraviolet region (200$400 \mathrm{~nm}$ ) and $\lambda_{\max }$ is observed at $270 \mathrm{~nm}$. The UV-vis absorbance of sample has no obvious change when the dose is less than $100 \mathrm{kGy}$, while the absorbance at $270 \mathrm{~nm}$ is proportional to dose at the dose more than $100 \mathrm{kGy}$. Up to our best knowledge, the $\pi \rightarrow \pi^{*}$ transition (substituent delocalized by aryl; $\mathrm{K}$ band) of aromatic hydrocarbons is about 220-250 nm, and the $\mathrm{n} \rightarrow \pi^{*}$ transition of simple carbonyl chromophore is nearly at $270 \mathrm{~nm}$ [26]. The absorption of unirradiated BPC6 at $270 \mathrm{~nm}$ was attributed to $\pi \rightarrow \pi^{*}$

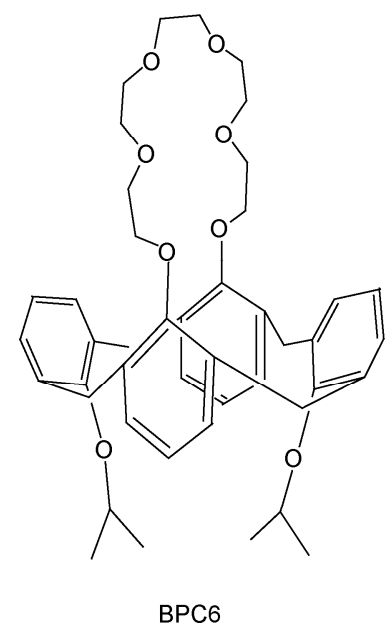<smiles>CC(C)Oc1ccccc1</smiles>

IB

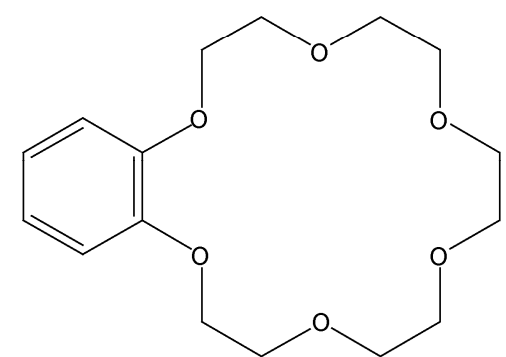

BC

Figure 1 Structures of BPC6, IB and BC. 


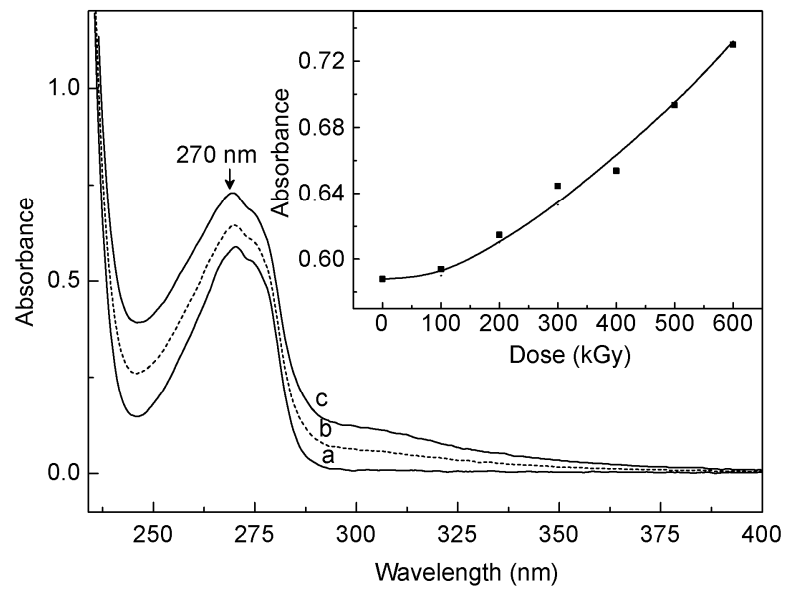

Figure 2 UV-vis spectra of the samples containing BPC6 irradiated at different doses. (a) 0 , (b) 300 , (c) $600 \mathrm{kGy}$. The inset shows the dependence of light absorbance of irradiated BPC6 on the dose at $275 \mathrm{~nm}$. $[\mathrm{BPC} 6]=2.5 \times 10^{-4} \mathrm{~mol} \mathrm{~L}^{-1}$.

transition of calixarene structure of BPC6. The absorbance change of irradiated BPC6 at $270 \mathrm{~nm}$ might be ascribed to the change in substitutes of BPC6, but in our work, the absorbance change was probably attributed to the formation of carbonyl compounds in radiolytic products during $\gamma$-irradiation combing with the results of micro-FTIR of irradiated sample.

Micro-FTIR spectra of BPC6 before and after irradiation at different doses are compared in Figure 3. Absorption bands at around 1646 and $1727 \mathrm{~cm}^{-1}$ appear at $300 \mathrm{kGy}$, corresponding to unsaturated carbonyl stretching of benzoquinone [27] which is formed in the oxidation of calixarene structure and carbonyl compounds of radiolytic products due to the oxidation of isopropyl structure, respectively. It is in agreement with the UV-vis results, indicating the existence of carbonyl groups in radiolytic products. In addition,

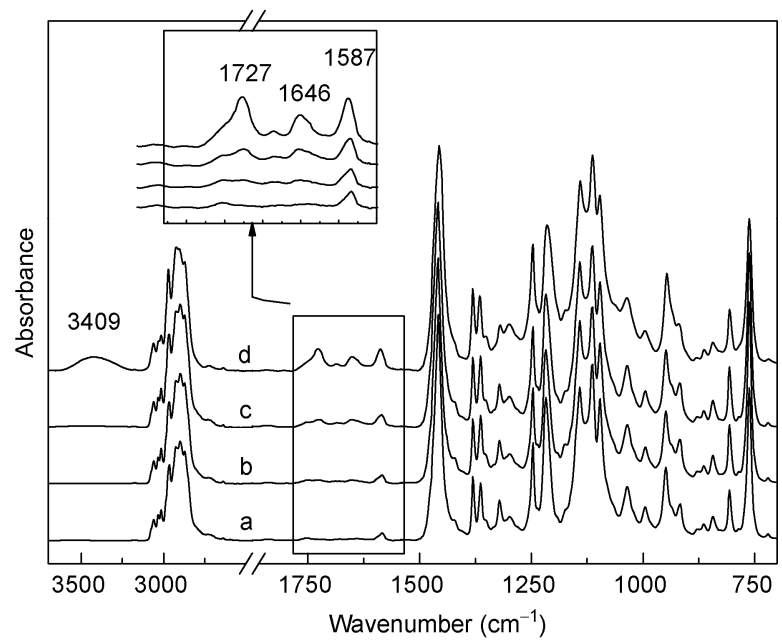

Figure 3 Micro-FTIR spectra of irradiated BPC6 at different doses. (a) 0, (b) 100, (c) 300, (d) $1000 \mathrm{kGy}$. the ketonization of BPC6 under the irradiation has been confirmed by ESI-MS [20]. Casnati et al. [24] reported that the phenolic hydroxyl groups of 25,27-dihydroxycalix[4] arene-crown- 6 exhibited an absorption band at $3360 \mathrm{~cm}^{-1}$. Absorption band at $3409 \mathrm{~cm}^{-1}$ for irradiated BPC6 implied the formation of radiolytic products containing phenolic hydroxyl groups during the irradiation. The difference between $3360 \mathrm{~cm}^{-1}$ in ref. [24] and $3409 \mathrm{~cm}^{-1}$ in this work is probably attributed to the different substituted groups of BPC6.

Figure 4 shows the relationship between dose and signal intensity of the functional groups in radiolytic products. Absorption bands at 1727,1646 and $1587 \mathrm{~cm}^{-1}$ remain unchanged at dose less than $100 \mathrm{kGy}$, which is consistent with UV-vis result. These results indicate BPC6 remained unchanged after irradiation at dose less than $100 \mathrm{kGy}$. The absorption bands at 1727 and $1646 \mathrm{~cm}^{-1}$ are enhanced with increasing dose at dose over $100 \mathrm{kGy}$. Absorption band at $1587 \mathrm{~cm}^{-1}$ corresponding to benzene skeleton vibration of calixarene structure has a positive correlation with the increasing dose. These results imply that calixarene structure of BPC6 has been obviously changed during the irradiation.

The low field ${ }^{1} \mathrm{H}$ NMR spectra of irradiated BPC6 at different doses were shown in Figure 5(a). The signal at near $8.0(\delta)$ corresponding to phenolic hydroxyl groups [24] appears at the dose more than $300 \mathrm{kGy}$. Furthermore, a new peak at about 10.4 is also presented when the absorbed dose increased to $1000 \mathrm{kGy}$, which is ascribed to phenolic hydroxyl groups [28], too. The difference of the chemical shift of phenolic hydroxyl groups in NMR spectra is attributed to the various substituted groups of CCEs. Besides, the signals at near 8.0 and 10.4 are enhanced greatly at high absorbed dose. According to NMR analysis, it is proposed that the radiolytic products containing phenolic hydroxyl groups are formed during the irradiation. The signal of phenolic hydroxyl groups appearing at 10.4 indicates the obvious change of crown structure of BPC6 when the dose is more

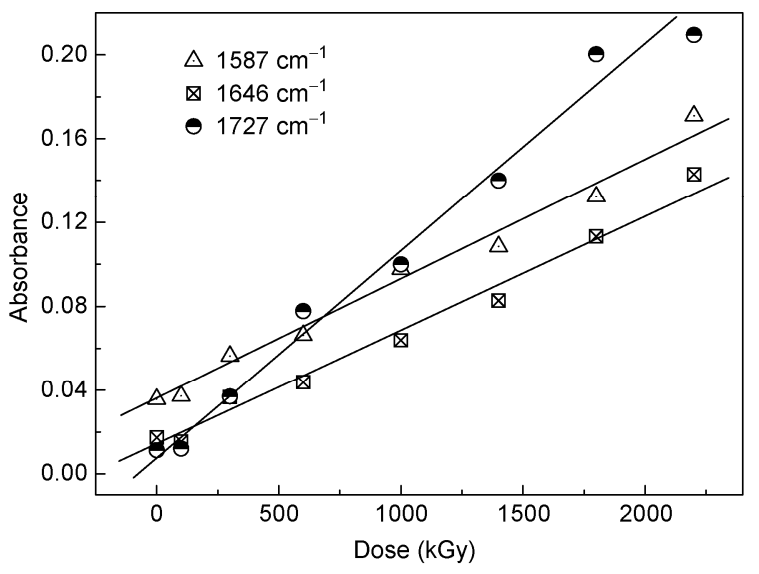

Figure 4 The relationship between dose and the intensity of absorption corresponding to the groups of radiolytic products. 
than $1000 \mathrm{kGy}$. Therefore, it can be concluded that the signal of phenolic hydroxyl groups shifting towards low field is due to the breakage and oxidation of crown structure in BPC6. ${ }^{1} \mathrm{H}$ NMR spectra of BPC6 before and after irradiation are compared in Figure 5(b). All the chemical shifts in ${ }^{1} \mathrm{H}$ NMR spectra are assigned to appropriate $\mathrm{H}$ atoms, which is in agreement with the reported literature [24]. Compared with that of unirradiated BPC6, the signal at 1.56 (trace of water in $\mathrm{CDCl}_{3}$ ) [29] is broadened and shifted towards low field in irradiated BPC6 (Figure S2). The addition of nitric acid in unirradiated BPC6 can also result in a similar phenomenon. Therefore, it is suggested that the hydrogen ion is formed during the irradiation, similarly to what has been reported on radiation effects of ionic liquid $\left[\mathrm{C}_{4} \mathrm{mim}\right]\left[\mathrm{PF}_{6}\right]$ [19].

$\mathrm{FeCl}_{3}$ test is a traditional colorimetric determination for phenolic hydroxyl groups, because the compounds containing phenolic hydroxyl groups can complex with $\mathrm{FeCl}_{3}$ [30,31]. Therefore, $\mathrm{FeCl}_{3}$ is used to further identify the phenolic hydroxyl groups of radiolytic products formed during the irradiation. $\mathrm{FeCl}_{3}$ solution $\left(\left[\mathrm{FeCl}_{3}\right] \approx 1 \times 10^{-2} \mathrm{~mol} \mathrm{~L}^{-1}\right.$ in ethanol) was mixed with BPC6 $\left([\mathrm{BPC} 6] \approx 2 \times 10^{-2} \mathrm{~mol} \mathrm{~L}^{-1}\right.$ in ethanol) before (solution-A) and after irradiation at 2200 kGy (solution-B), respectively (the inset in Figure 6). The color of solution-A is still light yellow, while the color of solution-B is changed into dark purple. These results indicate that the radiolytic products can complex with $\mathrm{FeCl}_{3}$ to form a complex compound. UV-vis spectra of BPC6 before and after irradiation combined with $\mathrm{FeCl}_{3}$ ethanol solution are shown in Figure. 6. An absorption band located at 441 $\mathrm{nm}$ is observed after irradiation at $2200 \mathrm{kGy}$. It is also in agreement with both the results of ${ }^{1} \mathrm{H}$ NMR and Micro-FTIR analysis. Therefore, it is concluded that the main radiolytic products contain phenolic hydroxyl groups.

\subsection{The radiolytic behavior of IB and BC under $\gamma$-irradiation}

The structure of BPC6 mainly contains crown ether and isopropyl groups. The radiolytic behavior of IB and BC under $\gamma$-irradiation was investigated as model chemicals for elucidating the radiolytic mechanism of BPC6. Compared with that of unirradiated IB, the light absorbance of irradiated IB at different doses is strengthened (Figure S3). ${ }^{1} \mathrm{H}$ NMR spectra of irradiated IB at different doses are shown in Figure 7, a new peak at around 9.34 corresponding to phenolic hydroxyl groups was observed for irradiated IB at $300 \mathrm{kGy}$. The results indicated the isopropyl groups were broken during the irradiation of IB, leading to formation of radiolytic products containing phenolic hydroxyl groups, which was also supported by Micro-FTIR of irradiated IB at 1000 kGy) (Figures S4 and S5).

Herein, NMR spectra of irradiated BC at different doses are shown in Figure 8. A signal near 8.2 appears when the dose is up to $1800 \mathrm{kGy}$ (Figure $8(\mathrm{a})$ ), which indicates the formation of radiolytic products containing phenolic hydroxyl groups during the irradiation. The cleavage of crown ether structure of dicyclohexano-18-crown- 6 had been confirmed at $1500 \mathrm{kGy}$ in previous literature [32]. Furthermore, the absorption bands at $3500 \mathrm{~cm}^{-1}$ (hydroxyl groups) and $1641 \mathrm{~cm}^{-1}$ (unsaturated carbonyl groups) can be observed in Micro-FTIR spectra (Figure S6). The result implies the ring opening of crown ether structure of BC results in the formation of phenolic hydroxyl groups and unsaturated carbonyl groups. All the chemical shifts in the ${ }^{1} \mathrm{H}$ NMR are assigned to appropriate $\mathrm{H}$ atoms, which is consistent with the reference [33]. Compared with unirradiated BC, no obvious changes in the NMR spectra were observed, implying that the chemical structure of $\mathrm{BC}$ is changed slightly when the dose is less than $1400 \mathrm{kGy}$ (The mole ratio of nonvolatile radiolytic products is less than $1 \%$ in irradiated $\mathrm{BC}$ ). It is also confirmed by Micro-FTIR and ${ }^{13} \mathrm{C}$ NMR (Figures S6 and S7). Crown ether structure of BC is broken and phenolic hydroxyl groups are formed when the dose is more than $1400 \mathrm{kGy}$. The signal at 1.75 is broadened and shifted towards low field with increasing dose from ${ }^{1} \mathrm{H}$ NMR result (Figure $8(\mathrm{~b})$ ), which is similar with that of BPC6. Therefore,
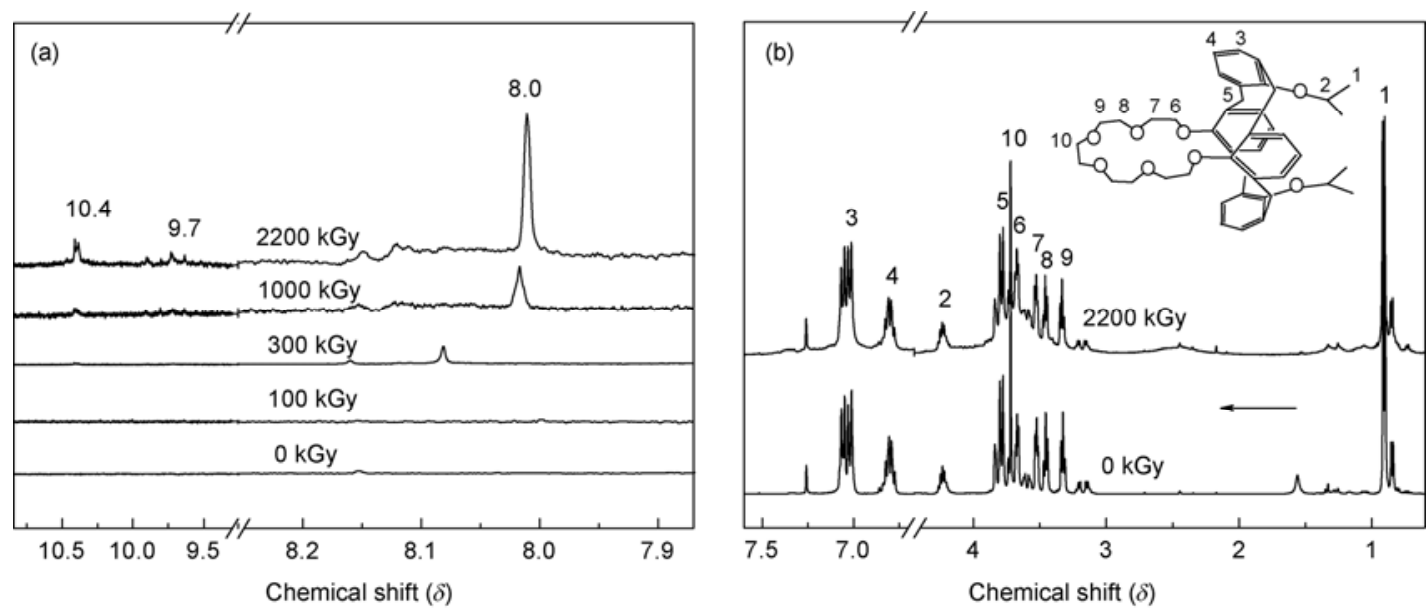

Figure 5 (a) The low field ${ }^{1} \mathrm{H}$ NMR spectra of irradiated BPC6 at different doses, and (b) the ${ }^{1} \mathrm{H}$ NMR spectra of BPC6 before and after $\gamma$-irradiation at $2200 \mathrm{kGy}$ 


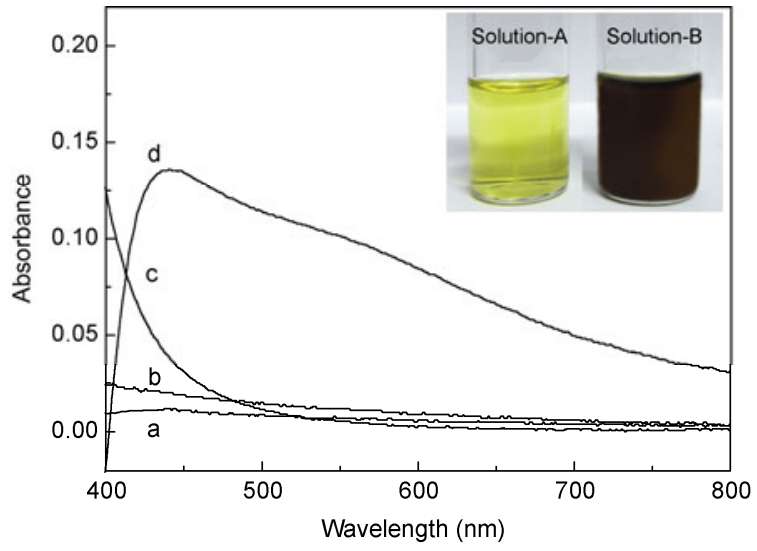

Figure 6 UV-vis spectra of $\mathrm{BPC} 6$ and $\mathrm{FeCl}_{3}$ in ethanol solution. (a) Unirradiated BPC6 with $\mathrm{FeCl}_{3}$ mixture; (b) unirradiated BPC6; (c) BPC6 (irradiated at $2200 \mathrm{kGy}$ ); (d) mixture of BPC6 (irradiated at $2200 \mathrm{kGy}$ ) with $\mathrm{FeCl}_{3}$. The inset shows the color of solution-A and solution-B.

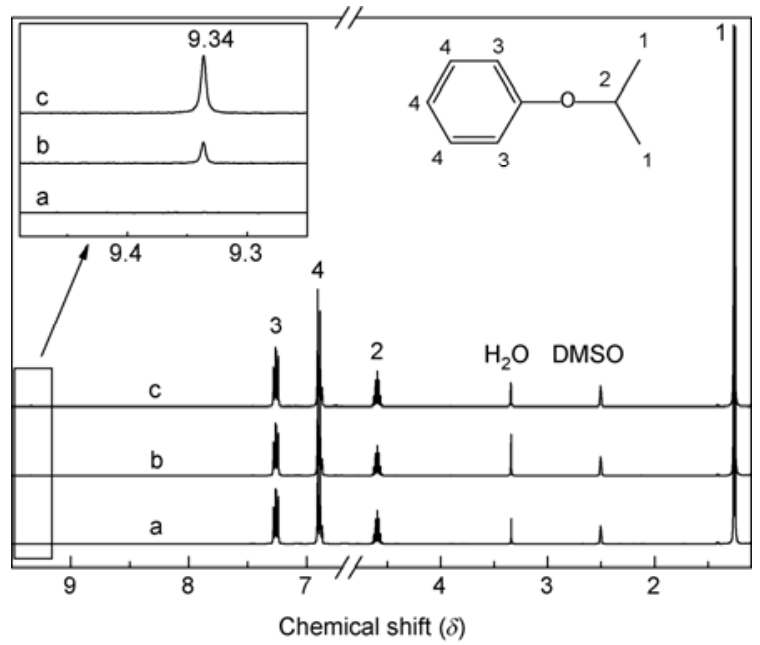

Figure $7 \quad{ }^{1} \mathrm{H}$ NMR spectra of irradiated IB at different doses. (a) 0 , (b) 300 , (c) $1000 \mathrm{kGy}$ (DMSO- $d_{6}$ was used as solvent in the measurements).

hydrogen ions could be formed during the irradiation of $\mathrm{BC}$ with high dose.

\subsection{The radiolytic mechanism of BPC6 under $\gamma$-irradiation}

The above results suggest that the dominant radiolytic products of BPC6 vary with the dose. Combining with the radiolytic behavior of $\mathrm{IB}$ and $\mathrm{BC}$, the procedure of radiation degradation of BPC6 under $\gamma$-irradiation can be proposed as follows: (1) the breakage of isopropyl structure of BPC6 is the dominant reaction at dose above $300 \mathrm{kGy}$ (Scheme 1), and the dealkylation of BPC6 results in the formation of radiolytic products containing phenolic hydroxyl groups. Several kinds of fragment molecules from the dealkylation of BPC6 have been reported in literatures [20,22], which are consistent with our results. In the presence of oxygen, the radiolytic products containing the carbonyl groups are
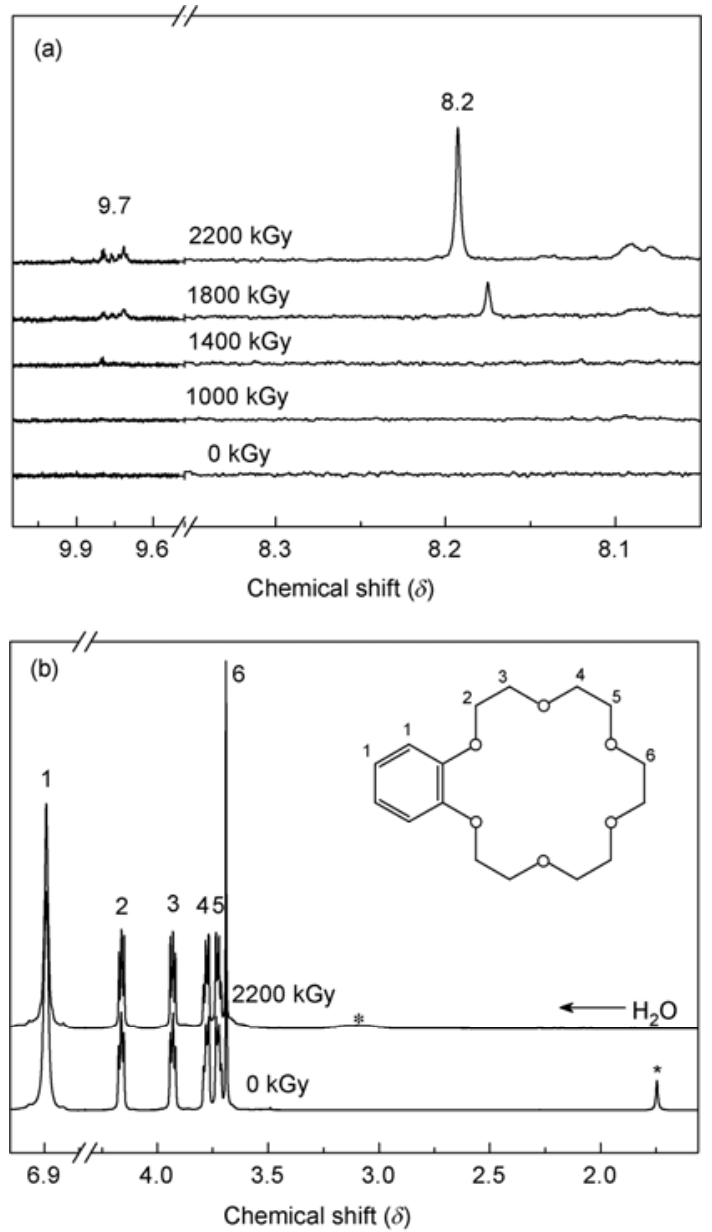

Figure 8 (a) The low field ${ }^{1} \mathrm{H}$ NMR spectra of $\mathrm{BC}$ irradiated at different doses. (b) ${ }^{1} \mathrm{H}$ NMR spectra of BC before and after $\gamma$-irradiation at $2200 \mathrm{kGy}$.

generated in the irradiated BPC6. The oxidation of radiolytic products containing phenolic hydroxyl groups results in the formation of unsaturated carbonyl groups of benzoquinone; (2) from the results of ${ }^{1} \mathrm{H}$ NMR of irradiated BPC6 and that of irradiated BC, the crown ether structure of BPC6 could be destroyed and ring-opening reaction became dominant, when the dose is more than $1000 \mathrm{kGy}$. Finally, the ring opening and oxidation of the crown ether structure of BPC6 results in the formation of phenolic hydroxyl groups, carbonyl groups and unsaturated carbonyl groups (Scheme 1).

\section{Conclusions}

In summary, the influence of $\gamma$-irradiation on BPC6 has been systematically investigated by various spectroscopic methods. The present results suggested that the chemical structure of irradiated BPC6 varied with the dose. BPC6 exhibited excellent radiation stability at dose less than 100 $\mathrm{kGy}$. Based on the investigation on the radiation stability of IB and BC, the possible radiolytic mechanism of BPC6 under $\gamma$-irradiation was proposed. During the $\gamma$-irradiation, both 


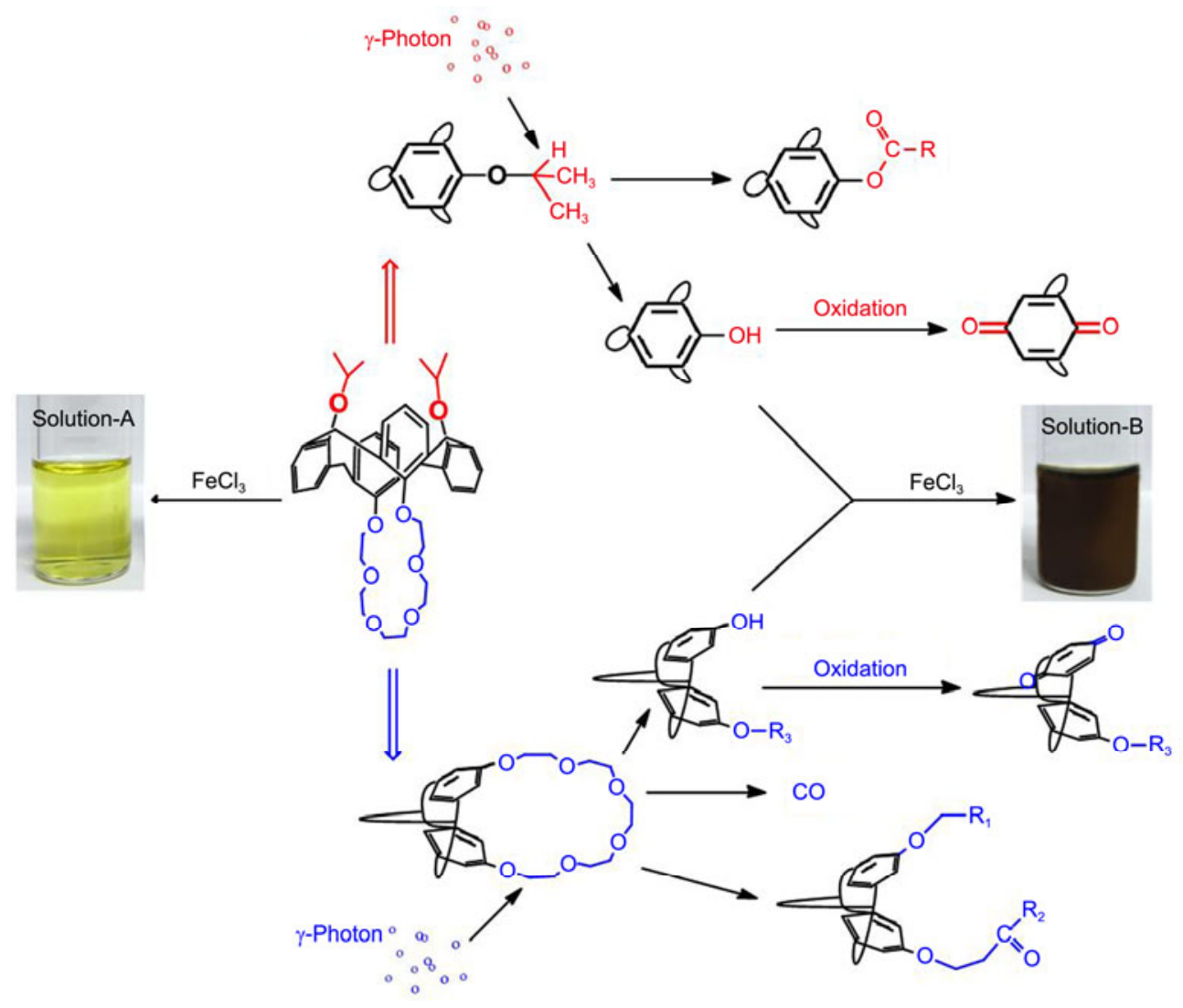

Scheme 1 The possible radiolysis mechanism of BPC6.

dealkylation of isopropyl structure in BPC6 and breakage of crown ether structure in BPC6 could result in the formation of phenolic hydroxyl groups. Besides, the formation of the radiolytic products containing phenolic hydroxyl groups during $\gamma$-irradiation of BPC6 was confirmed using $\mathrm{FeCl}_{3}$ as a probe, which is a new and effective method for analyzing the trace radiolytic products of BPC6.

This work was supported by the National Natural Science Foundation of China $(91126014,11079007,21073008)$ and Research Fund for the Doctoral Program of Higher Education of China (20100001110021).

1 Kim J S, Pang J H, Yu I Y, et al. Calix[4]arene dibenzocrown ethers as caesium selective extractants. J Chem Soc-Perkin Trans, 1999, 837-846

2 Casnati A, Della Ca'N, Sansone F, et al. Enlarging the size of calix[4]arene-crowns- 6 to improve $\mathrm{Cs}^{+} / \mathrm{K}^{+}$selectivity: A theoretical and experimental study. Tetrahedron, 2004, 60: 7869-7876

3 Sessler J L, Kim S K, Gross D E, et al. Crown-6-calix[4]arenecapped calix[4]pyrrole: An ion-pair receptor for solvent-separated CsF ions. J Am Chem Soc, 2008, 130: 13162-13166

4 Dabestani R, Ji H F, Brown G M, et al. A new highly selective calix [4]crown-6 fluorescent caesium probe. Chem Commun, 2000, 833834

5 Brodbelt J S, Goolsby B J, Adou E, et al. Determination of alkali metal ion binding selectivities of calixarenes by matrix-assisted laser desorption ionization and electrospray ionization in a quadrupole ion trap. Int J Mass spectrom, 1999, 193: 197-204

6 Xu C, Yuan L Y, Shen X H, et al. Efficient removal of caesium ions from aqueous solution using a calix crown ether in ionic liquids: Mechanism and radiation effect. Dalton Trans, 2010, 39: 3897-3902

7 Kriz J, Dybal J, Makrlik E, et al. Interaction of cesium ions with calix [4]arene-bis( $t$-octylbenzo-18-crown-6): NMR and theoretical study. J Phys Chem B, 2011, 115: 7578-7587

8 Sieffert N, Chaumont A, Wipff G. Importance of the liquid-liquid interface in assisted ion extraction: New molecular dynamics studies of cesium picrate extraction by a calix 4 arene. J Phys Chem C, 2009, 113: $10610-10622$

9 Korovitch A, Mulon J B, Souchon V, et al. Kinetics, thermodynamics, and modeling of complex formation between calix 4 biscrowns and cesium. J Phys Chem B, 2009, 113: 14247-14256

10 Blanda M T, Farmer D B, Brodbelt J S, et al. Synthesis and alkali metal ion binding properties of two rigid sterochemical isomers of calix[6]arene bis-crown-4. J Am Chem Soc, 2000, 122: 1486-1491

11 Thuery P, Nierlich M, Bryan J C, et al. Crown ether conformations in 1,3-calix[4]arene bis(crown ethers): Crystal structures of a caesium complex and solvent adducts and molecular dynamics simulations. J Chem Soc-Dalton Trans, 1997, 4191-4202

12 Ungaro R, Casnati A, Ugozzoli F, et al. 1,3-Dialkoxycalix[4]arenecrowns-6 in 1,3-alternate conformation-Cesium-selective ligands that exploit cation-arene interactions. Angew Chem Int Ed, 1994, 33: 1506-1509

13 Hagege A, Safi S, Asfari Z, et al. Synthesis and characterization of immunogens based on calix[4]arene-crown- 6 for the generation of antibodies directed towards cesium ions. Bioconjugate Chem, 2006, 17: $1346-1350$

14 Sachleben R A, Urvoas A, Bryan J C, et al. Dideoxygenated calix[4] arene crown- 6 ethers enhanced selectivity for caesium over potassium and rubidium. Chem Commun, 1999, 1751-1752

15 Cue D, Bouguet-Bonnet S, Morel-Desrosiers N, et al. Behavior of cesium and thallium cations inside a calixarene cavity as probed by nuclear spin relaxation. Evidence of cation-pi interactions in water. $\mathbf{J}$ 
Phys Chem B, 2009, 113: 10800-10807

16 Sieffert N, Wipff G. Comparing an ionic liquid to a molecular solvent in the cesium cation extraction by a calixarene: A molecular dynamics study of the aqueous interfaces. J Phys Chem B, 2006, 110: 19497-19506

17 Shkrob I A, Marin T W, Dietz M L. On the radiation stability of crown ethers in ionic liquids. J Phys Chem B, 2011, 115: 3903-3911

18 Marin T W, Shkrob I A, Dietz M L. Hydrogen-bonding interactions and protic equilibria in room-temperature ionic liquids containing crown ethers. J Phys Chem B, 2011, 115: 3912-3918

19 Yuan L Y, Peng J, Xu L, et al. Influence of gamma-radiation on the ionic liquid [C(4)mim][PF6] during extraction of strontium ions. Dalton Trans, 2008, 6358-6360

20 Jankowski C K, Allain F, Dozol J F, et al. Preliminary study of the stability of calix[4]arene crown compounds under radiolysis. Rapid Commun Mass Spectrom, 2003, 17: 1247-1255

21 Jankowski C K, Hocquelet C, Arseneau S, et al. Laser-induced dealkylation of calix[4]arene-crown-6 ethers. J Photochem Photobiol A, 2006, 184: 216-220

22 Lamouroux C, Aychet N, Lelievre A, et al. High-performance liquid chromatography with electrospray ionisation mass spectrometry and diode array detection in the identification and quantification of the degradation products of calix[4]arene crown-6 under radiolysis. Rapid Commun Mass Spectrom, 2004, 18: 1493-1503

23 Jankowski C K, Allain F, Lamouroux C, et al. Comparison of the stability of calix[4]arene-crown-6-cation binary complexes under electrospray mass spectrometry. Spectr Lett, 2003, 36: 327-340

24 Casnati A, Pochini A, Ungaro R, et al. Synthesis, complexation, and membrane-transport studies of 1,3-alternate calix[4]arene-crown-6
conformers-A new class of cesium selective ionophores. J Am Chem Soc, 1995, 117: 2767-2777

25 Asfari Z, Thuery P, Nierlich M, et al. Unsymmetrical calix[4]-biscrowns-6 with unequivalent crown loops. Tetrahedron Lett, 1999, 40: 499-502

26 Pretsch E, Hlmann B P, Affolter C. Structure Determination of Organic Compounds Tables of Spectral Data. 4th ed. Berlin Heidelberg: Springer-Verlag, 2009

27 Ge M, Wang W F, Zhao H W, et al. Characterization of crystal transformation in the solid-state by terahertz time-domain spectroscopy. Chem Phys Lett, 2007, 444: 355-358

28 Lou X L, Cheng F, Cao P F, et al. Self-assembled supramolecular nanocarrier hosting two kinds of guests in the site-isolation state. Chem Eur J, 2009, 15: 11566-11572

29 Gottlieb H E, Kotlyar V, Nudelman A. NMR chemical shifts of common laboratory solvents as trace impurities. J Org Chem, 1997, 62: 7512-7515

30 Wesp E F, Brode W R. The absorption spectra of ferric compounds. I. The ferric chloride-phenol reaction. J Am Chem Soc, 1934, 56: 1037-1042

31 Soloway S, Wilen S H. Improved ferric chloride test for phenols. Anal Chem, 1952, 24: 979-983

32 Abashkin V M, Wester D W, Campbell J A, et al. Radiation stability of cis-isomers of dicyclohexano-18-crown-6. Radiat Phys Chem, 1996, 48: 463-472

33 Zhang C J, Li S J, Zhang J Q, et al. Benzo-21-crown-7/secondary dialkylammonium salt [2]pseudorotaxane- and [2]rotaxane-type threaded structures. Org Lett, 2007, 9: 5553-5556

Open Access This article is distributed under the terms of the Creative Commons Attribution License which permits any use, distribution, and reproduction in any medium, provided the original author(s) and source are credited.

\section{Supporting Information}

Figure S1 The ESI-MS spectrum of unirradiated BPC6 solid.

Figure S2 The peak at near $1.56(\delta)$ (trace of water in $\left.\mathrm{CDCl}_{3}\right)$ is broadened and shifted towards low field in irradiated BPC6.

Figure S3 UV-vis spectra of the samples containing IB irradiated at different doses.

Figure S4 ${ }^{1} \mathrm{H}$ NMR spectrum of phenol ( $d$-DMSO was used as solvent in the measurement).

Figure S5 Micro-FTIR spectra of irradiated IB at different doses.

Figure S6 Micro-FTIR spectra of irradiated BC at different doses.

Figure S7 ${ }^{13} \mathrm{C}$ NMR spectra of BC before and after $\gamma$-irradiation at $1000 \mathrm{kGy}$ under air atmosphere $\left(\mathrm{CDCl}_{3}\right.$ was used as solvent in the measurement).

The supporting information is available online at csb.scichina.com and www.springerlink.com. The supporting materials are published as submitted, without typesetting or editing. The responsibility for scientific accuracy and content remains entirely with the authors. 